\title{
Information and decision-making needs among people with affective disorders - results of an online survey
}

This article was published in the following Dove Press journal:

Patient Preference and Adherence

4 May 2015

Number of times this article has been viewed

\section{Sarah Liebherz \\ Lisa Tlach \\ Martin Härter \\ Jörg Dirmaier}

Department of Medical Psychology, University Medical Center HamburgEppendorf, Hamburg, Germany
Correspondence: Sarah Liebherz Department of Medical Psychology, University Medical Center HamburgEppendorf, Martinistraße 52, W26,

D-20246 Hamburg, Germany

Tel +49 40741057969

Fax +49 40741054940

Email s.liebherz@uke.de
Background: Patient decision aids are one possibility for enabling and encouraging patients to participate in medical decisions.

Objective: This paper aims to describe patients' information and decision-making needs as a prerequisite for the development of high-quality, web-based patient decision aids for affective disorders.

Design: We conducted an online cross-sectional survey by using a self-administered questionnaire including items on Internet use, online health information needs, role in decision making, and important treatment decisions, performing descriptive and comparative statistical analyses.

Participants: A total of 210 people with bipolar disorder/mania as well as 112 people with unipolar depression participated in the survey.

Results: Both groups specified general information search as their most relevant information need and decisions on treatment setting (inpatient or outpatient) as well as decisions on pharmacological treatment as the most difficult treatment decisions. For participants with unipolar depression, decisions concerning psychotherapeutic treatment were also especially difficult. Most participants of both groups preferred shared decisions but experienced less shared decisions than desired.

Discussion and conclusion: Our results show the importance of information for patients with affective disorders, with a focus on pharmacological treatment and on the different treatment settings, and highlight patients' requirements to be involved in the decision-making process. Since our sample reported a chronic course of disease, we do not know if our results are applicable for newly diagnosed patients. Further studies should consider how the reported needs could be addressed in health care practice.

Keywords: bipolar disorder, computer/Internet technology, depression, empirical supported treatment, mood disorders, pharmacotherapy

\section{Introduction}

Over a third of the total European Union population suffers from mental disorders each year, with affective disorders being the most frequent mental illnesses. ${ }^{1}$ Only a small proportion of persons affected receive adequate medical care. ${ }^{1,2}$ One barrier in seeking professional care may result from a lack of information on illness symptoms and treatment options. Patient education (including web-based) is one relevant option to address these barriers. Patient education and patient involvement are relevant components of shared decision making (SDM). SDM is defined as an interactional process in which the patient and the physician aim to reach a decision together that is based on shared information and the best available evidence. ${ }^{3}$ In the course of this process, 
the physician supports the patient in weighing the costs, benefits, and possible consequences of different diagnostic or therapeutic options against each other in order to come to a shared and informed decision. ${ }^{4} \mathrm{SDM}$ is considered a fundamental part of patient-centered mental health care. ${ }^{5-7}$ Evidence suggests that the majority of users suffering from mental disorders prefer to be involved in treatment decision making ${ }^{8-11}$ and that patient involvement in mental health care is associated with enhanced patient satisfaction, empowerment, and guideline-concordant care. ${ }^{5,12-14}$ However, studies examining the degree of SDM being practiced in mental health treatment indicate low levels of SDM practice. ${ }^{15-19}$

One way to enable and encourage patients to participate in medical decisions is to provide high-quality and feasible patient decision aids (PtDAs). PtDAs are evidence-based tools that support people in deliberating, independently or in collaboration with others, about choices they face by considering relevant attributes of the options. These tools also forecast how people might feel about short, intermediate, and long-term outcomes in ways which help the process of constructing preferences and eventual decision making. ${ }^{20}$ PtDAs may be helpful when there is more than one evidencebased treatment (or screening) option. ${ }^{21}$ Research in many areas of medicine have shown that PtDAs increase patient involvement in decision making, knowledge of their options, the feeling of being informed, and the proportion of patients with realistic expectations of the chances of benefits and harms and also lead to reduced decisional conflict. ${ }^{22}$

Assessment of service users' and experts' views on the information and decision-support needs is suggested as being one key element in the systematic development of high-quality decision aids. ${ }^{23,24}$ LeBlanc et a ${ }^{25}$ describe the successful engagement of patients, clinicians, and stakeholders in the development and evaluation process of the Depression Medication Choice tool. Concerning affective disorders, there is some evidence on information and decisional needs for unipolar depressed patients ${ }^{18,26-30}$ but not for bipolar patients. Tlach et $\mathrm{a}^{31}$ included these studies as well as six studies addressing patients with schizophrenia in a systematic review focusing on information as well as decisional needs. No studies were found for the other mental disorders. Overall, seven information needs categories were identified, with the categories basic facts, treatment, and coping being of major relevance. Concerning decision making needs, decisions on medication and treatment setting were most relevant.

Considering patients' health literacy skills is another current challenge when developing PtDAs, especially as lower health literacy affects decision-making outcomes (ie, higher decisional uncertainty) ${ }^{32}$ Unfortunately, there are only a few PtDAs addressing the needs of lower health literacy users. ${ }^{32}$ Including potential users when developing PtDAs may be one option for addressing their health literacy skills.

Concerning affective disorders, some health organizations (such as healthwise ${ }^{\circledR}$, the Agency for Healthcare Research and Quality, and the National Health Service [NHS]) provide PtDAs on different depression-related topics; PtDAs for patients with bipolar disorder are rare - maybe due to the lower prevalence rate of this condition compared to unipolar depression. Most PtDAs on affective disorders focus on decisions concerning medication - for example, if the patient should take medication or not, ${ }^{33}$ which medication to take, ${ }^{34}$ or if a pregnant woman should take medication. ${ }^{35}$

A current project, being part of the public-funded intersectoral research network psychenet - the Hamburg Network for Mental Health, aims to develop and evaluate an e-mental health portal (www.psychenet.de), with PtDAs for patients with affective and other mental disorders as a key part. ${ }^{36}$ The PtDAs are to be developed based on international quality standards provided by the International Patient Decision Aid Standards (IPDAS) Collaboration. ${ }^{37}$

\section{Objectives}

To provide the topical evidence about patients' information needs and decisional conflicts, we conducted an online survey for patients with various mental disorders. As the number of online health information resources (including PtDAs) is increasing, the consideration of online health information needs appears especially relevant. As needs assessment is one major part of the development process of PtDAs, the aim of our study was to explore information and decision-making needs of people with affective disorders. We addressed the following questions:

1. What are the preferred as well as the experienced roles of people with affective disorders in the decision-making process?

2. What kind of information needs do people with affective disorders have?

3. What kind of treatment decisions did people with affective disorders already face and how difficult were the decisions?

4. Are there differences between the two diagnostic groups with regard to their information and decision-making needs?

\section{Materials and methods}

We conducted an online cross-sectional survey using a selfadministered questionnaire. 


\section{Survey development}

Our questionnaire involved items for sociodemographic (age, sex, level of education, marital status, country of birth) and clinical (self-reported primary diagnosis, illness duration, treatment experience) characteristics. The main part focuses on four topics:

1. Internet use (three items).

2. Online health information needs (two items).

3. Role in decision making (preferred as well as experienced role in decision making with two items adapted from Degner et al's Control Preferences Scale). ${ }^{38}$

4. Treatment decisions (16 items concerning evidence-based treatment options [identified through systematic literature and guideline search]. The items included the following topics: treatment setting, start of treatment, psychopharmacological treatment, psychotherapeutic treatment, combined treatment, and alternative treatment. Participants stated if they ever had made these decisions and [if yes] assessed the difficulty of these decisions [very difficult, rather difficult, rather simple, very simple]. Participants had the possibility to specify other relevant decisions in free text fields).

The survey was pilot-tested with 27 participants (research assistants and student assistants) and coordinated with different experts in the field of SDM research. The items were derived from evidence-based treatment options named in the current German national disease management guidelines. ${ }^{39,40}$ Since these options differ between different mental health conditions (ie, to do "watchful waiting" is a relevant treatment option for mild unipolar depression but not for bipolar disorder), the questions were tailored depending on the mental illness stated. Since our survey was developed as a prerequisite for the development of web-based PtDAs, we decided to examine an online sample.

\section{Data collection}

We performed this survey with Enterprise Feedback Suite (EFS) survey. Participants were recruited online on our e-mental health portal, www.psychenet.de. Additionally, we contacted 48 cooperating self-help groups as well as ten cooperating hospitals in the area of Hamburg, Germany via email to announce our survey. The hospitals posted our announcement on their information boards. The German Association for Bipolar Disorders (DGBS) (www.dgbs.de) announced the survey on their website and on their forum.

Hamburg's medical association's ethics committee gave a positive vote and all participants were asked for written informed consent. Detailed information sheets on study purposes, data security, and declaration of consent were provided.
Only patients who gave written informed consent to participate (asked at the beginning of the questionnaire) as well as consent to data use (asked when participants had finished the questionnaire) were included in the analyses. To give written informed consent, participants had to accept the statements that they agree to participate in the study and that they answered all questions in a meaningful way and agree to data use - since we wanted to exclude people different from the target population (for example, researchers), that may have completed the survey without answering the questions in a meaningful way.

Participants reporting experience with bipolar disorder/ mania or unipolar depression as a patient and who were at least 18 years old were included. People with other mental health conditions also completed the survey, but the present paper considers only these two conditions.

\section{Data analysis}

For all calculations, we used PASW Statistics 18. The statistics used are primarily descriptive (percentages, means, and standard deviations). To determine significant differences between the two diagnostic groups, we used chi-square tests (providing chi-square coefficients $\chi^{2}$ and phi coefficients $\varphi)$ for categorical and $t$-tests for interval or ratio scaled variables. We considered a probability value $P<0.05$ (exact significance, two-tailed) as significant.

\section{Results \\ Patient flow}

During the investigation period from January to April 2013, $\mathrm{N}=930$ people who experienced mental disorders as a patient started the online survey. From 493 participants who gave informed consent, $\mathrm{n}=210$ reported experience with bipolar disorder/mania and $n=112$ reported experience with unipolar depression. The other participants $(n=171)$ reported experiences with other mental disorders, mostly anxiety disorders $(n=60)$, and these results are reported elsewhere. ${ }^{41}$ Other mental disorders reported by the participants were schizophrenia/ psychosis $(n=28)$, eating disorder $(n=22)$, somatoform disorder ( $\mathrm{n}=12)$, high-risk alcohol consumption/alcohol dependency $(n=6)$, or other $(n=27$; for example, borderline disorder or posttraumatic stress disorder). Some participants $(\mathrm{n}=16)$ did not know their diagnosis. Since the diagnostic distribution of the initial sample $(\mathrm{N}=930)$ is unknown, it was not possible to calculate diagnosis-specific response rates.

\section{Sample description}

More than two-thirds of all participants were female. Age ranged from 18 to 77 years. Most participants reported a 
chronic course of their mental disorder. While participants with symptoms of bipolar disorder reported significantly more treatment episodes than participants with symptoms of unipolar depression, including specialized physician and hospital treatment, the two groups did not differ significantly concerning all other sociodemographic and clinical characteristics (Table 1).

\section{Internet use and online health information needs}

A greater proportion of participants with symptoms of bipolar disorder use the Internet on a daily basis, compared to people with unipolar depression (daily use $93.3 \%$ versus $\left.84.8 \% ; \chi^{2}[1, \mathrm{~N}=322]=8.33 ; P<0.05, \varphi=0.16\right)$. They also used the Internet more often for general health information searches $(49.5 \%$ versus $33.0 \%$ minimum once a week up to daily; $\left.\chi^{2}[1, \mathrm{~N}=322]=11.74 ; P<0.05, \varphi=0.19\right)$ as well as for specific health information searches on their mental disorder $\left(\chi^{2}[1, \mathrm{~N}=322]=20.33 ; P<0.001, \varphi=0.25\right)$ (Figure 1).

The most prevalent reason for online health information searches was the need for general information on the particular mental illness (bipolar disorder/mania or unipolar depression). The three topics considered most relevant by participants of both indications were "general information", "information about treatment options", and "tips on dealing with the disease" (Table 2).

\section{Role in decision making Preferred role}

The majority of both groups preferred shared decisions (Figure 2). Thirty-one percent of participants with symptoms of bipolar disorder and $41 \%$ of participants with symptoms of unipolar depression preferred an autonomous decision by themselves. In both groups, only 5\% wanted the physician to decide alone. The two groups did not differ significantly

Table I Sociodemographic and clinical characteristics

\begin{tabular}{|c|c|c|c|c|c|}
\hline & \multicolumn{2}{|c|}{$\begin{array}{l}\text { Bipolar disorderl } \\
\text { mania }(n=2 \mid 0)\end{array}$} & \multicolumn{2}{|c|}{$\begin{array}{l}\text { Unipolar } \\
\text { depression }(n=|| 2)\end{array}$} & \multirow{2}{*}{$\begin{array}{l}\text { Statistical tests } \\
\text { for between- } \\
\text { group differences }\end{array}$} \\
\hline & $\mathbf{n}$ & $\%$ & $\mathbf{n}$ & $\%$ & \\
\hline Sex & & & & & $\chi^{2}(2, \mathrm{~N}=322)=0.27$ \\
\hline Female & 146 & 69.5 & 79 & 70.5 & $P=0.95, \varphi=0.03$ \\
\hline Male & 63 & 30.0 & 32 & 28.6 & \\
\hline Other & 1 & 0.5 & I & 0.9 & \\
\hline Age in years ( $M, S D$, range) & \multicolumn{2}{|c|}{44.5 (I2.2) 19-74 } & \multicolumn{2}{|c|}{42.0 (12.7) 18-77 } & $t_{(320)}=-1.71, P=0.09$ \\
\hline Education & & & & & $\chi^{2}(2, \mathrm{~N}=322)=\mid .31$ \\
\hline $8-10$ years & 66 & 31.4 & 41 & 36.6 & $P=0.52, \varphi=0.06$ \\
\hline More than 10 years & 130 & 61.9 & 62 & 55.4 & \\
\hline $\begin{array}{l}\text { Other (still at school, without } \\
\text { graduation, other) }\end{array}$ & 14 & 6.7 & 9 & 8.0 & \\
\hline Partnership & & & & & $\chi^{2}(\mathrm{I}, \mathrm{N}=322)=2.0 \mathrm{I}$ \\
\hline In a stable relationship & 126 & 60.0 & 58 & 51.8 & $P=0.19, \varphi=-0.08$ \\
\hline Country of birth & & & & & $\chi^{2}(1, N=321)=0.16$ \\
\hline Germany & 193 & 91.9 & 102 & 91.1 & $P=0.83, \varphi=-0.02$ \\
\hline $\begin{array}{l}\text { Illness duration in years } \\
\text { (M, SD, range) }\end{array}$ & \multicolumn{2}{|c|}{$19.9(12.4) \mathrm{I}-60$} & \multicolumn{2}{|c|}{$|7.0(\mid 3.3)|-55$} & $t_{(320)}=-1.92, P=0.06$ \\
\hline \multicolumn{6}{|c|}{ Treatment experience (for mental disorders) } \\
\hline Already been in treatment & 201 & 95.7 & 97 & 86.6 & $\begin{array}{l}\chi^{2}(\mathrm{I}, \mathrm{N}=322)=8.78 \\
P<0.0 \mathrm{I}, \varphi=-0.17\end{array}$ \\
\hline GP & 123 & 58.6 & 56 & 50.0 & $\begin{array}{l}\chi^{2}(I, N=298)=0.33 \\
P=0.6 I, \varphi=0.03\end{array}$ \\
\hline $\begin{array}{l}\text { Specialist physician (eg, psychiatrist, } \\
\text { neurologist) }\end{array}$ & 189 & 90.0 & 70 & 62.5 & $\begin{array}{l}\chi^{2}(\mathrm{I}, \mathrm{N}=298)=27.50 \\
\mathrm{P}<0.00 \mathrm{I}, \varphi=0.30\end{array}$ \\
\hline Psychotherapist & 147 & 70.0 & 74 & 66.1 & $\begin{array}{l}\chi^{2}(I, N=298)=0.34 \\
P=0.58, \varphi=-0.03\end{array}$ \\
\hline $\begin{array}{l}\text { Hospital (eg, psychiatric hospital, } \\
\text { psychosomatic clinic, day clinic) }\end{array}$ & 164 & 78.1 & 59 & 52.7 & $\begin{array}{l}\chi^{2}(\mathrm{I}, \mathrm{N}=298)=14.98 \\
P<0.00 \mathrm{I}, \varphi=0.22\end{array}$ \\
\hline Initial treatment years ( $M, S D$, range) & \multicolumn{2}{|c|}{$13.7(10.6) 0-46$} & \multicolumn{2}{|c|}{$12.5(10.7) \mathrm{I}-50$} & $t_{(296)}=-0.87, P=0.39$ \\
\hline
\end{tabular}

Abbreviations: GP, general practitioner; M, mean; SD, standard deviation. 


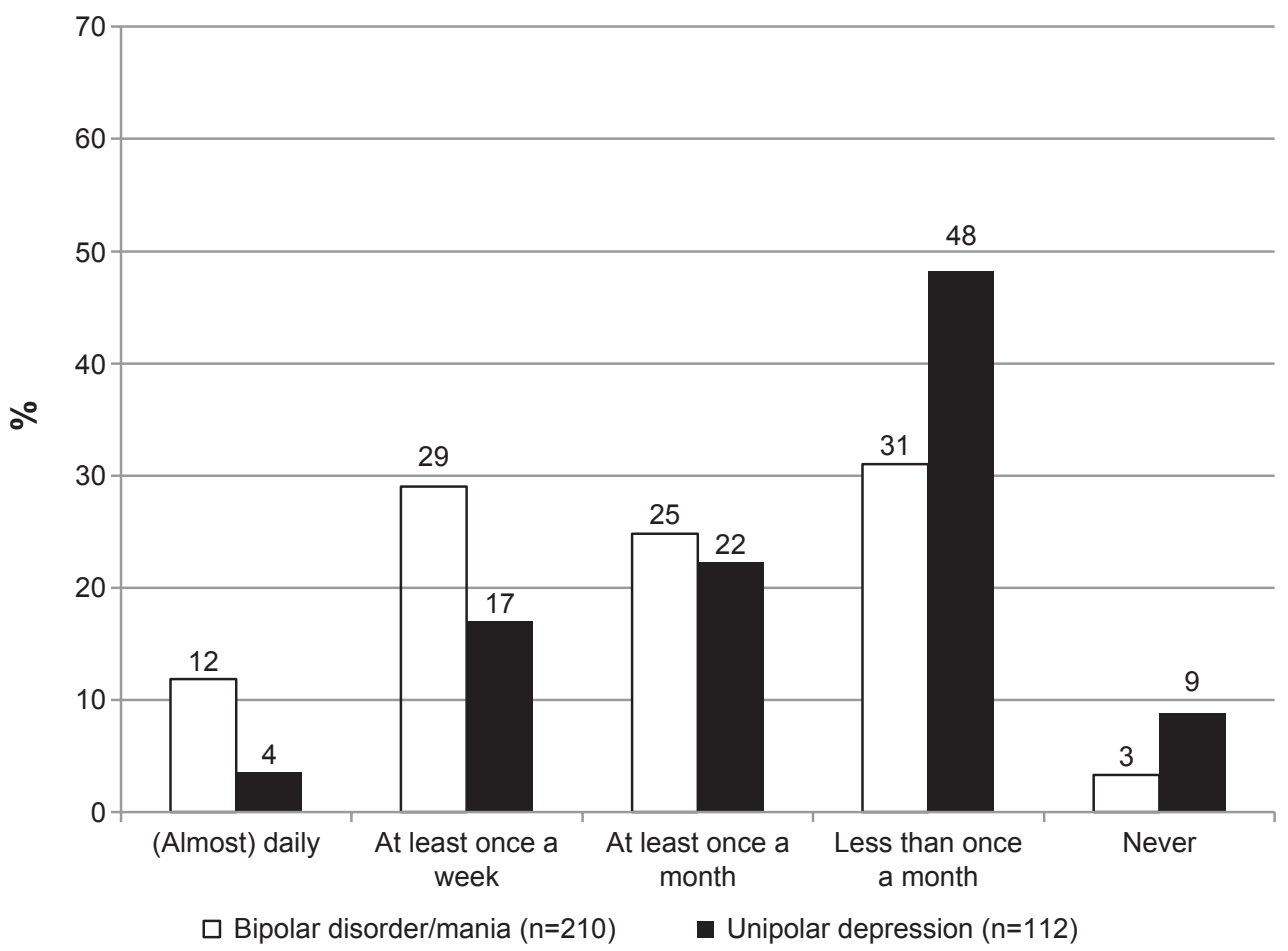

Figure I Frequency of participants' use of the Internet to search for information about bipolar disorder/mania or unipolar depression.

Table 2 Online health information needs

\begin{tabular}{|c|c|c|c|c|}
\hline & \multicolumn{2}{|c|}{$\begin{array}{l}\text { Bipolar disorder/mania } \\
(\mathrm{n}=2 \mid 0)\end{array}$} & \multicolumn{2}{|c|}{$\begin{array}{l}\text { Unipolar } \\
\text { depression }(n=|| 2)\end{array}$} \\
\hline & $\mathbf{n}$ & $\%$ & $\mathbf{n}$ & $\%$ \\
\hline \multicolumn{5}{|c|}{ For what reasons have you been searching the Internet for information about bipolar disorder/mania/unipolar depression? } \\
\hline \multicolumn{5}{|l|}{ was not sufficient. } \\
\hline $\begin{array}{l}\text { The information my physician/psychotherapist provided } \\
\text { was difficult to understand. }\end{array}$ & 8 & 3.8 & 5 & 4.5 \\
\hline $\begin{array}{l}\text { I did not agree with the information my } \\
\text { physician/psychotherapist provided. }\end{array}$ & 31 & 14.8 & 16 & 14.3 \\
\hline $\begin{array}{l}\text { It was recommended by my physician/psychotherapist } \\
\text { to read up on bipolar disorder/mania/unipolar depression. }{ }^{\text {a }}\end{array}$ & 47 & 22.4 & 6 & 5.4 \\
\hline I am looking for a physician/psychotherapist. & 33 & 15.7 & 28 & 25.0 \\
\hline $\begin{array}{l}\text { I wanted to inform myself generally about bipolar } \\
\text { disorder/mania/unipolar depression. }{ }^{\mathrm{a}}\end{array}$ & 158 & 75.2 & 78 & 69.6 \\
\hline \multicolumn{5}{|c|}{ What sort of information on bipolar disorder/mania/unipolar depression ${ }^{\mathrm{a}}$ were you looking for? } \\
\hline \multicolumn{5}{|l|}{ (symptoms, causes, course of the disease). } \\
\hline Information about treatment options (eg, psychotherapy, drugs). & 157 & 74.8 & 63 & 56.3 \\
\hline \multicolumn{5}{|l|}{ treatment options. } \\
\hline \multicolumn{5}{|l|}{ (eg, where can I get treatment?). } \\
\hline $\begin{array}{l}\text { Information about self-help groups/experience exchange } \\
\text { with others who are affected/reported experiences of those affected. }\end{array}$ & 123 & 58.6 & 33 & 29.5 \\
\hline Information for relatives. & 46 & 21.9 & 13 & 11.6 \\
\hline Tips on dealing with the disease (eg, coping with everyday life, self-help). & 153 & 72.9 & 63 & 56.3 \\
\hline
\end{tabular}

Notes: 'All questions were tailored to the participants' self-reported diagnoses: participants with symptoms of bipolar disorder/mania were asked about their information search concerning bipolar disorder/mania, and participants with symptoms of unipolar depression were asked about their information search concerning depressive disorder. 


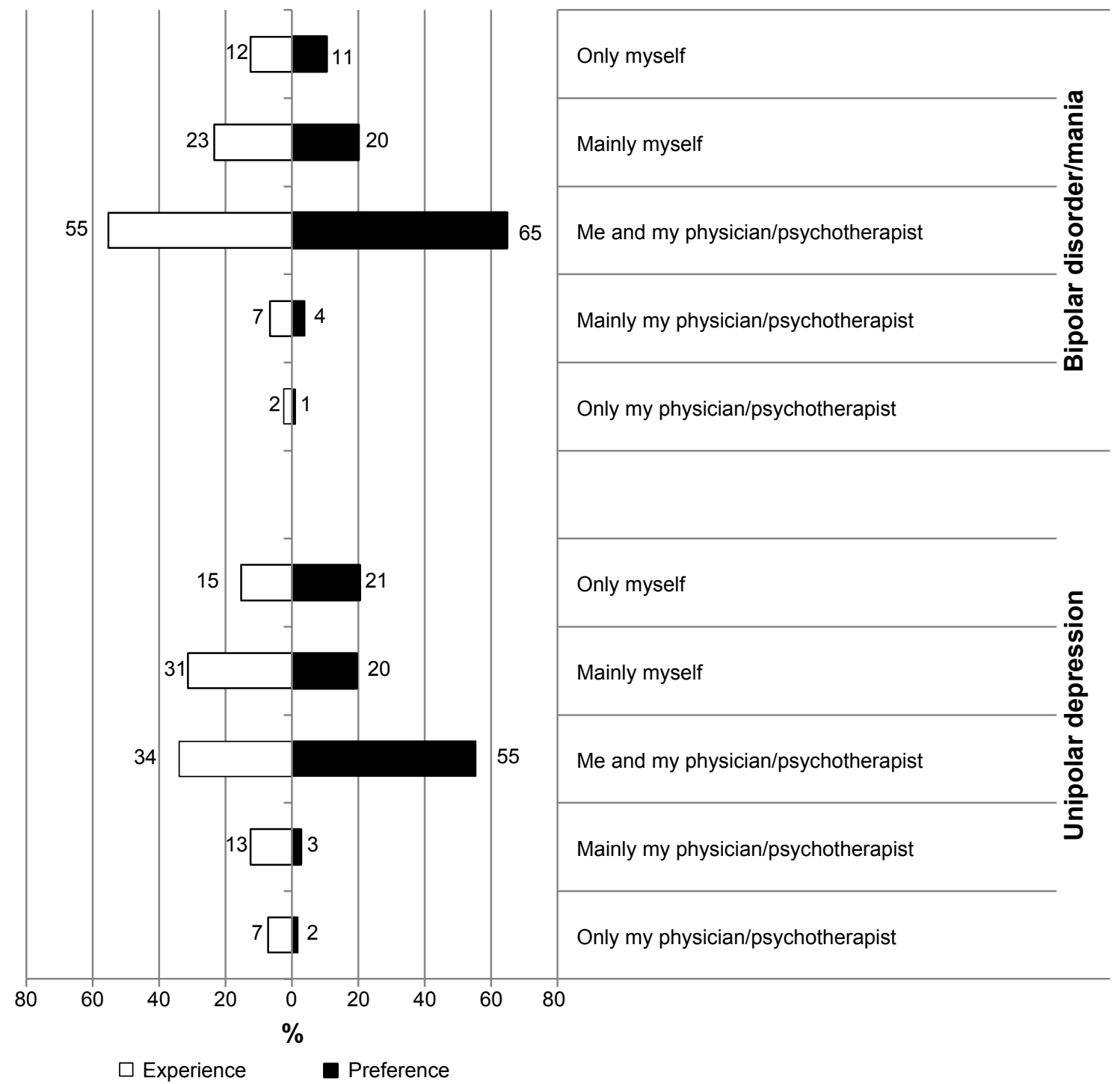

Figure 2 Preferred and experienced decision-making roles.

Notes: Bipolar disorder/mania: $\mathrm{n}=210$; unipolar depression: $\mathrm{n}=1 \mathrm{I} 2$.

with regard to their role preference $\left(\chi^{2}[1, \mathrm{~N}=322]=7.06\right.$; $P=0.13, \varphi=0.15)$.

\section{Experienced role}

We also asked for participants' experiences in the last consultation: $55 \%$ of all participants with symptoms of bipolar disorder and $34 \%$ of all participants with symptoms of unipolar depression remembered it as a shared decision. Both groups reported more decisions made alone (by patient or physician) than they preferred (difference between preferred and experienced decisions in participants with symptoms of bipolar disorder: $\chi^{2}[1, \mathrm{~N}=210]=120.55 ; P<0.001, \varphi=0.76$ and in participants with symptoms of unipolar depression: $\chi^{2}$ $[1, N=112]=41.36 ; P<0.001, \varphi=0.61)$. The latter experienced more exclusive decisions by their physician $(20 \%)$ than did participants with symptoms of bipolar disorder (9\%)
(Figure 2). The experienced role differed significantly between the two groups $\left(\chi^{2}[1, \mathrm{~N}=322]=16.08 ; P<0.01\right.$, $\varphi=0.22$ ).

\section{Treatment decisions and decisional conflicts}

Treatment decisions classified as "rather difficult" or "very difficult" by the majority (more than 50\%) of participants with symptoms of bipolar disorder concerned the treatment setting (inpatient or outpatient) as well as the psychopharmacological treatment (taking another medication or a different dose) (Figure 3). Decisions concerning medication (dose change, deposition of medication, kind of medication, taking medication or not) were made by at least $90 \%$ of these participants. Decisions considered less relevant for the majority of participants with symptoms of 


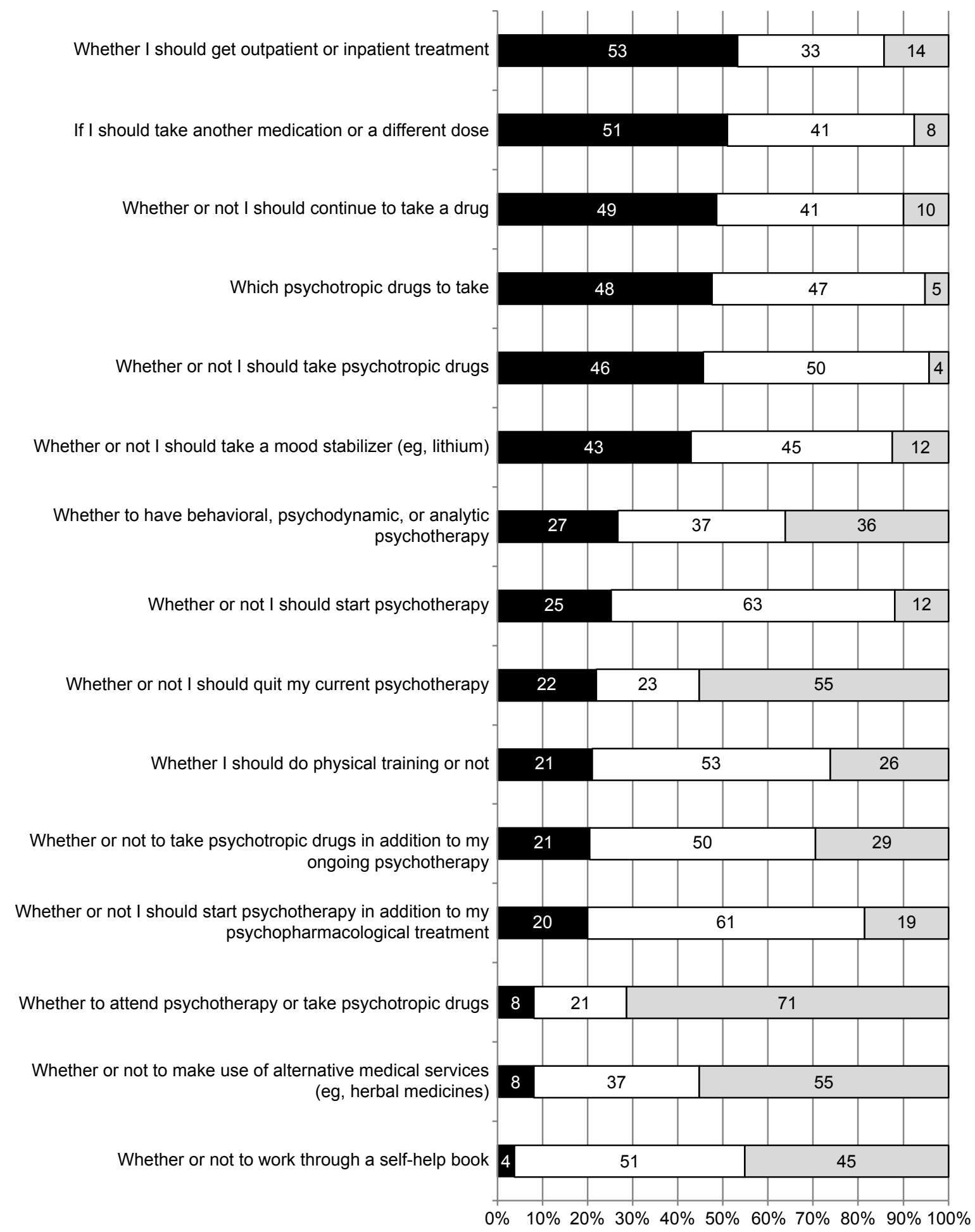

- Decisions classified as "rather difficult" or "very difficult" a Decisions classified as "rather simple" or "very simple" $\square$ Not made this decision yet

Figure 3 Relevant treatment decisions of participants with bipolar disorder/mania $(n=2 \mid 0)$.

bipolar disorder $(50 \%$ or more had not made this decision yet) were: psychotherapy or psychotropic drugs, the application of alternative treatments, or the decision to quit one's current psychotherapy.
None of the decisions was considered as difficult by the majority (more than 50\%) of participants with symptoms of unipolar depression, but decisions about the treatment setting and about psychopharmacological treatment (taking another 
medication or a different dose, whether or not to take psychotropic drugs) were also among the most difficult (considered as difficult by more than $40 \%$ of these participants). More than one-third of these participants mentioned some decisions on psychotherapy as difficult (starting psychotherapy or not; quitting one's current psychotherapy or not; whether to have behavioral, psychodynamic, or analytic psychotherapy). To do watchful waiting or not, which is also an evidencebased treatment option for patients with mild unipolar depression, was also mentioned as a difficult decision by about one-third of these participants. The decisions considered as less relevant ( $50 \%$ or more had not made this decision yet) for participants with symptoms of unipolar depression were the decision between psychotherapy and medication, the decision to work through a self-help book, and the decision about the application of alternative treatments (Figure 4).

In the free text field, participants from both conditions mentioned other relevant decision topics, for example, decisions concerning dealing with the illness (eg, acceptance of the illness, to disclose one's illness, considering the option of suicide), other treatment decisions (eg, changing the health care provider), decisions concerning occupational life (early retirement, finding a suitable job/suitable working hours, applying for a severely handicapped pass), and decisions about partnerships/family (breaking up, getting pregnant, putting responsibility on one's partner). Participants with symptoms of unipolar depression also mentioned the decision to give up or to continue the search for a treatment possibility. For some participants with symptoms of bipolar disorder, the handling of their manic phases was especially relevant. Some participants with symptoms of bipolar disorder also had to decide whether they could live alone or not and whether they should attend a self-help group or not.

\section{Discussion and conclusion}

\section{Summary}

To prepare PtDAs for the e-mental health portal www. psychenet.de, we surveyed 210 participants with symptoms of bipolar disorder/mania as well as 112 participants with symptoms of unipolar depression in an online survey. This large number of participants highlights the relevance of this subject.

Both groups specified general information searches as their most relevant information need and decisions on treatment setting (inpatient or outpatient) as well as decisions on pharmacological treatment as the most difficult treatment decisions. For participants with symptoms of unipolar depression, decisions concerning psychotherapeutic treatment were also especially difficult.
The problem of choosing between inpatient and outpatient treatment may reflect the challenge of noticing if the aggravation of symptoms is beyond the scope of outpatient treatment possibilities. In bipolar disorders, psychiatric inpatient treatment is a relevant treatment option for detailed diagnostic clarification, in manic or severely depressive phases (eg, in case of endangerment of self and others) or in case of complex therapeutic or social challenges. ${ }^{39}$ Indications for patients with unipolar depression are similar: inpatient treatment is recommended in case of suicidality or when the patient is at risk of harming others, severe symptoms, treatment resistance, comorbidity, interaction effects of different drugs, psychotic symptoms, depressive stupor, or diagnostic uncertainty. ${ }^{40}$ For affected people, not only the classification of the symptoms' severity may be challenging, but also the acceptance that an inpatient admission is indicated, since many patients have had unpleasant experiences or unpleasant ideas of (compulsory) inpatient treatment, and compulsory measures in particular are discussed critically. ${ }^{42}$

Participants with symptoms of bipolar disorder and participants with symptoms of unipolar depression did not differ significantly with regard to their preferred role in decision making. According to the previous literature, ${ }^{8-11}$ participants from both groups mostly preferred shared decisions. There were significant differences between the groups in decisionmaking experiences, with unipolar depressive participants experiencing more decisions made by their physician alone than bipolar participants. This may result from the specific symptoms (inaction of depressive patients) or from the difference between the two samples: the participants with symptoms of bipolar disorder report more treatment experience and may therefore be more involved in the treatment process. The difference between preferred and experienced roles in decision making (less shared decisions than desired by patients) is concordant with the previous literature. ${ }^{8-10,43}$

While this is the first study on information and decisional needs of people with bipolar disorder, there is some evidence on these issues for patients with unipolar depression. ${ }^{18,26-30}$ Their strongest decision-making needs concerned medication and treatment setting, ${ }^{31}$ therefore, the results presented here are in line with the existing evidence. However, this study reveals new evidence concerning patients with bipolar disorder - their information and decisional needs have not been studied before.

As there were hardly any instruments for determining patients' information and decision-making needs, we provided a new compilation of questions on information needs and decision-making needs concerning evidence-based treatment options. 
Whether I should take another medication or a different dose

Whether I should get outpatient or inpatient treatment

Whether or not I should take psychotropic drugs

Whether or not I should start psychotherapy

Whether I should wait and see if my symptoms get better by themselves or start treatment directly

Whether or not I should quit my current psychotherapy

Whether to have behavioral, psychodynamic, or analytic psychotherapy

Whether or not I should continue to take a drug

Which psychotropic drugs to take

Whether I should do physical training or not

Whether or not to take psychotropic drugs in addition to my ongoing psychotherapy

Whether or not I should start psychotherapy in addition to my psychopharmacological treatment

Whether to attend psychotherapy or take psychotropic drugs

Whether or not to work through a self-help book

Whether or not to make use of alternative medical services (eg, herbal medicines)

$$
0 \%
$$

- Decisions classified as "rather difficult" or "very difficult"

$\square$ Not made this decision yet

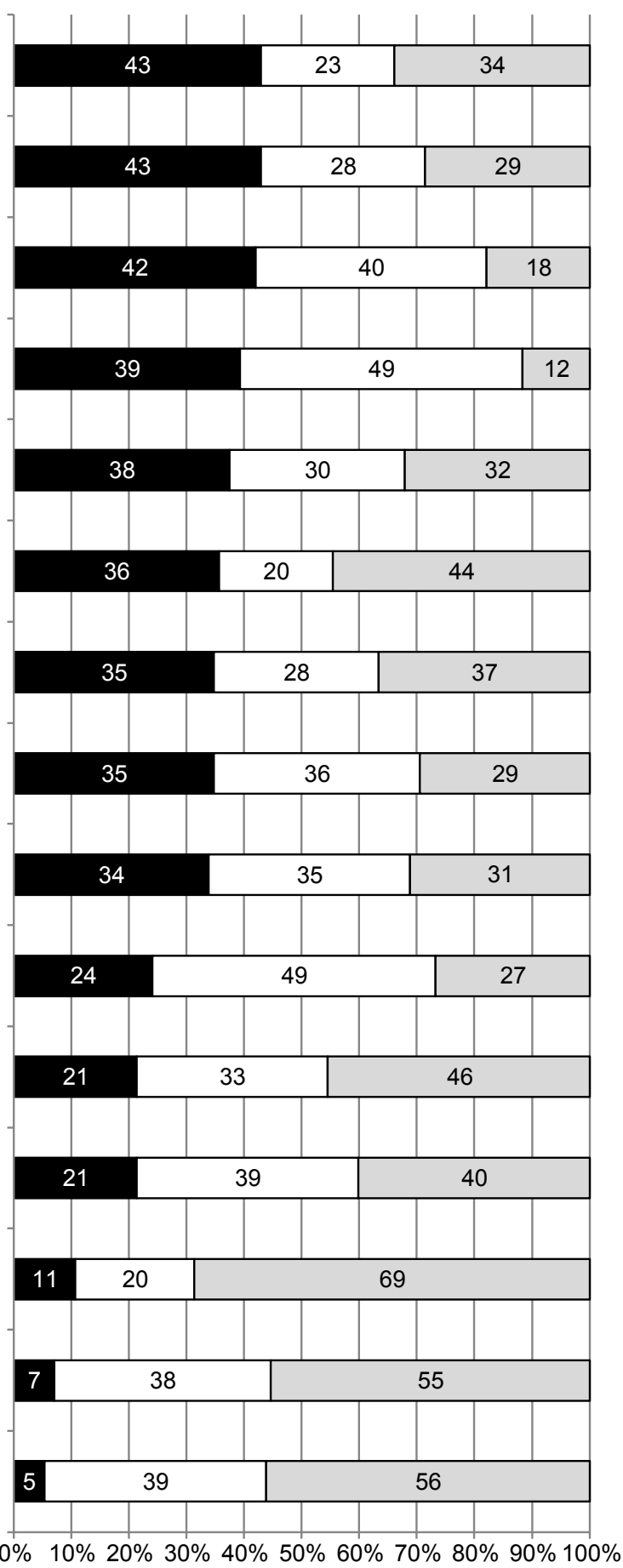

口 Decisions classified as "rather simple" or "very simple"

Figure 4 Relevant treatment decisions of participants with unipolar depression ( $n=\mid$ I2).

\section{Limitations}

There are some limitations regarding the representativeness of the sample. As psychenet is a project in the metropolitan area of Hamburg, our website is probably especially well known in this region. We also announced our online survey in selfhelp organizations in this region. However, the nationwide
DGBS in particular supported our survey, with an announcement on their website and on their forum. This allowed us to survey a large but also selected sample of participants with bipolar disorder. They reported more experience with Internet searches for health information as well as more experience with the health care system (for example, specialist and 
inpatient treatment) than did participants with symptoms of unipolar depression. In this respect, the two samples are not completely comparable. Furthermore, the selectivity of our sample regarding the chronic course of illness restricts the generalizability of our results. Additionally, almost all (96\% of all participants with symptoms of bipolar disorder and $87 \%$ of all participants with symptoms of a depression) reported treatment experiences, whereas, in the German adult population, only $67 \%$ of persons with a lifetime diagnosis of bipolar disorder (54\% of persons with major depression and $62 \%$ of persons with dysthymia) report lifetime mental health service use. ${ }^{44} \mathrm{On}$ the one hand, the strong treatment-seeking behavior in our sample may reflect the chronicity and severity of the participants' illnesses. On the other hand, our participants may generally be more engaged with their illnesses.

If we had studied a sample of newly diagnosed patients, our results would have been different, for example, concerning the decisions they already faced. However, it is helpful to know experienced peoples' opinions, since newly diagnosed patients are not yet able to make judgments about treatment options that may be relevant in the future. On the other hand, online health information needs of newly diagnosed patients may differ from experienced patients' needs, and our results are not transferable to this group.

However, the female-to-male sex ratio in our sample is representative in the participants reporting unipolar depression (2.5:1 in our sample versus 2.3:1 in European epidemiological studies). ${ }^{1}$ Regarding participants with symptoms of bipolar disorder, there is a disproportionately high number of women in our sample (2.3:1 versus 1.2:1 in European epidemiological studies).

Moreover, as we used self-reported diagnoses, the validity of diagnoses is restricted. In addition, we only considered patients' perspectives and did not include relatives' or experts' views on information and decision-making needs in these analyses. It is noticeable that the decision between psychotherapy and pharmacotherapy was not relevant for the majority of participants. Since this decision depends on the symptoms' severity, which was not considered here, we do not know for how many patients it should have been relevant. The insignificance of this decision could be due to different reasons: 1) the samples' symptom severity (it is only relevant for patients with moderate unipolar depression but not for patients with mild or severe depression, as psychopharmacological therapy is not recommended for mild unipolar depression, whereas patients with severe unipolar depression ought to receive both treatments); 2) a lack of information on guideline-based treatment from the health care provider; or 3) personal preferences.
Our self-administered questionnaire was implemented for the first time; results are therefore not completely comparable to others.

Finally, we decided to restrict our survey to treatment decisions, so we could not systematically record other relevant decisions in the course of the disease (eg, decisions concerning partnerships or work). However, we offered the possibility to specify other decisions in a free text field. This enabled us to record these decisions, but it does not offer the possibility to compare the relevance of these decisions to the treatment decisions.

\section{Practice implications}

This paper emphasizes the desire to participate in treatment decisions in a large proportion of people with affective disorders. In both groups, decisions concerning the treatment setting or pharmacological treatments were the most difficult ones. This highlights the need for information on these issues. In this respect, health care providers should consider patients' information and decisional needs including their individual preferred role in decision making; additionally, PtDAs should address these decision-making topics.

As severe mental disorders are seen as chronic illnesses, decision support might need to comprise multiple decision points along the course of disease and multiple delivery settings. ${ }^{45}$ According to this, we identified patients' information and decisional priorities. Thus, the results of this survey gave indications on the thematic focus of PtDAs, we are currently developing for the e-mental health portal www. psychenet.de. The PtDAs are available at http://entscheidungshilfen.psychenet.de/entscheidungshilfen-uebersicht. html. The content of a currently developed PtDA on unipolar depression is based on the current treatment guidelines ${ }^{40,46}$ and on the results of this survey, and was also reviewed by affected persons as well as experts in the field of depression treatment and research.

To confirm our presumptions, more qualitative (to identify specific questions concerning medications and treatment setting to be answered in a PtDA) as well as quantitative research seems reasonable - especially with newly diagnosed participants. Further studies should also consider how patients' needs could be addressed in health care practice.

\section{Acknowledgments}

Psychenet is a project network funded by the German Federal Ministry of Education and Research (funding code 01KQ1002B) in the region of Hamburg which consists of more than 80 scientific and medical institutions, counseling 
centers, the Senate and the Chamber of Commerce of the Free and Hanseatic City of Hamburg, and companies, as well as patients' and relatives' associations (2011-2014). The vision of the project is to promote mental health today and in the future, concerning early diagnosis and effective treatment of mental illnesses. For more information and a list of all partners, please visit www.psychenet.de. The funding source had no influence on the study design, the data analysis and interpretation, the writing of the manuscript, or the decision to submit the paper for publication in Patient Preference and Adherence. We would like to thank Iris Extra for her support in data analysis of the free text fields as well as two anonymous reviewers for their helpful comments.

\section{Author contributions}

SL, LT, MH, and JD designed the study and prepared the online survey; SL analyzed and interpreted the data; LT, $\mathrm{MH}$, and JD contributed to the interpretation of the data; SL drafted the manuscript; and LT, MH, and JD critically reviewed the manuscript. All authors saw and approved the final version of the manuscript.

\section{Disclosure}

The authors report no conflicts of interest in this work.

\section{References}

1. Wittchen HU, Jacobi F, Rehm J, et al. The size and burden of mental disorders and other disorders of the brain in Europe 2010. Eur Neuropsychopharmacol. 2011;21(9):655-679.

2. Wang PS, Lane M, Olfson M, Pincus HA, Wells KB, Kessler RC. Twelve-month use of mental health services in the United States: results from the National Comorbidity Survey Replication. Arch Gen Psychiatry. 2005;62(6):629-640.

3. Härter M. [Shared decision making - from the point of view of patients, physicians and health politics is set in place]. Z Arztl Fortbild Qualitatssich. 2004;98(2):89-92. German.

4. Elwyn G, Laitner S, Coulter A, Walker E, Watson P, Thomson R. Implementing shared decision making in the NHS. BMJ. 2010;341:c5146.

5. Duncan E, Best C, Hagen S. Shared decision making interventions for people with mental health conditions. Cochrane Database Syst Rev. 2010;(1):CD007297.

6. Richter M, Schmid-Ott G, Muthny F. [Information and participation of patients in psychosomatic rehabilitation. Occurrence and relations to patient satisfaction treatment outcome]. Psychiatr Prax. 2011;38(5): 237-243. German.

7. Storm M, Edwards A. Models of user involvement in the mental health context: intentions and implementation challenges. Psychiatr $Q$. 2013;84(3):313-327.

8. Adams JR, Drake RE, Wolford GL. Shared decision-making preferences of people with severe mental illness. Psychiatr Serv. 2007;58(9): 1219-1221.

9. Hamann J, Neuner B, Kasper J, et al. Participation preferences of patients with acute and chronic conditions. Health Expect. 2007;10(4): 358-363.

10. Patel SR, Bakken S, Ruland C. Recent advances in shared decision making for mental health. Curr Opin Psychiatry. 2008;21(6):606-612.
11. Hamann J, Mendel R, Reiter S, et al. Why do some patients with schizophrenia want to be engaged in medical decision making and others do not? J Clin Psychiatry. 2011;72(12):1636-1643.

12. Clever SL, Ford DE, Rubenstein LV, et al. Primary care patients' involvement in decision-making is associated with improvement in depression. Med Care. 2006;44(5):398-405.

13. Tambuyzer E, Van Audenhove C. Is perceived patient involvement in mental health care associated with satisfaction and empowerment? Health Expect. Epub 2013 Feb 21.

14. Joosten EA, DeFuentes-Merillas L, de Weert GH, Sensky T, van der Staak CP, de Jong CA. Systematic review of the effects of shared decision-making on patient satisfaction, treatment adherence and health status. Psychother Psychosom. 2008;77(4):219-226.

15. Goossensen A, Zijlstra P, Koopmanschap M. Measuring shared decision making processes in psychiatry: skills versus patient satisfaction. Patient Educ Couns. 2007;67(1-2):50-56.

16. Goss C, Moretti F, Mazzi MA, Del Piccolo L, Rimondini M, Zimmermann C. Involving patients in decisions during psychiatric consultations. Br J Psychiatry. 2008;193(5):416-421.

17. McCabe R, Khanom H, Bailey P, Priebe S. Shared decision-making in ongoing outpatient psychiatric treatment. Patient Educ Couns. 2013; 91(3):326-328.

18. Simon D, Loh A, Wills CE, Härter M. Depressed patients' perceptions of depression treatment decision-making. Health Expect. 2007;10(1): 62-74.

19. Loh A, Simon D, Hennig K, Hennig B, Härter M, Elwyn G. The assessment of depressive patients' involvement in decision making in audio-taped primary care consultations. Patient Educ Couns. 2006;63(3):314-318.

20. Elwyn G, Frosch D, Rollnick S. Dual equipoise shared decision making: definitions for decision and behaviour support interventions. Implement Sci. 2009;4:75.

21. Adams M, Koch RW. Pharmacology: Connections to Nursing Practice. Upper Saddle River, NJ: Pearson Prentice Hall; 2010.

22. Stacey D, Légaré F, Col NF, et al. Decision aids for people facing health treatment or screening decisions. Cochrane Database Syst Rev. 2014;1:CD001431.

23. Elwyn G, O'Connor A, Stacey D, et al; International Patient Decision Aids Standards (IPDAS) Collaboration. Developing a quality criteria framework for patient decision aids: online international Delphi consensus process. BMJ. 2006;333(7565):417.

24. Jacobsen MJ, O'Connor AM, Stacey D. Decisional Needs Assessment in Populations: A Workbook for Assessing Patients' and Practitioners' Decision Making Needs. 1999 [updated 2013]. Available from: http:// decisionaid.ohri.ca/docs/implement/Population_Needs.pdf. Accessed March 26, 2015.

25. LeBlanc A, Shah ND, Herrin J, et al. Translation into practice of comparative effectiveness of depression medications: The depression medication choice decision aid trial. J Gen Intern Med. 2014;29 (1 Supplement):S239-S240.

26. Barney LJ, Griffiths KM, Banfield MA. Explicit and implicit information needs of people with depression: a qualitative investigation of problems reported on an online depression support forum. $B M C$ Psychiatry. 2011;11:88.

27. Llewellyn-Jones S, Gill J, Donnelly P. Questions patients ask psychiatrists. Psychiatr Bull R Coll Psychiatr. 2001;25:21-24

28. Mueser KT, Bellack AS, Wade JH, Sayers SL, Rosenthal CK. An assessment of the educational needs of chronic psychiatric patients and their relatives. Br J Psychiatry. 1992;160:674-680.

29. Stacey D, Menard P, Gaboury I, et al. Decision-making needs of patients with depression: a descriptive study. J Psychiatr Ment Health Nurs. 2008;15(4):287-295.

30. Wittmund B, Bischkopf J, Angermeyer MC. [Educational needs among spouses of depressive patients and their illness models of depression]. Gesundheitswesen. 2001;63(8-9):536-541. German.

31. Tlach L, Wüsten C, Daubmann A, Liebherz S, Härter M, Dirmaier J. Information and decision-making needs among people with mental disorders: a systematic review of the literature. Health Expect. Epub 2014 Aug 21. 
32. McCaffery KJ, Holmes-Rovner M, Smith SK, et al. Addressing health literacy in patient decision aids. BMC Med Inform Decis Mak. 2013;13 Suppl 2:S10.

33. Healthwise Staff. Depression: Should I Take an Antidepressant? [webpage on the Internet]. 2014. Available from: http://decisionaid.ohri.ca/ AZsumm.php?ID=1058. Accessed January 8, 2015.

34. Agency for Healthcare Research and Quality (AHRQ). Antipsychotic Medicines for Treating Schizophrenia and Bipolar Disorder. A Review of the Research for Adults and Caregivers. AHRQ Pub No 12(13)-EHC054-A. AHRQ; 2013. Available from: http://www. effectivehealthcare.ahrq.gov/ehc/products/146/1458/antipsychoticsadults-130410.pdf. Accessed January 8, 2015.

35. Healthwise Staff. Depression: Should I Take Antidepressants While I'm Pregnant? [webpage on the Internet]. 2013. Available from: http:// decisionaid.ohri.ca/AZsumm.php?ID=1161. Accessed January 8, 2015.

36. Härter M, Kentgens M, Brandes A, et al. Rationale and content of psychenet: the Hamburg Network for Mental Health. Eur Arch Psychiatry Clin Neurosci. 2012;262 Suppl 2:S57-S63.

37. Elwyn G, O'Connor AM, Bennett C, et al. Assessing the quality of decision support technologies using the International Patient Decision Aid Standards instrument (IPDASi). PLoS One. 2009;4(3):e4705.

38. Degner LF, Sloan JA, Venkatesh P. The Control Preferences Scale. Can J Nurs Res. 1997;29(3):21-43.

39. DGBS, DGPPN, eds. S3-Leitlinie zur Diagnostik und Therapie Bipolarer Störungen. Langversion [S3-Guideline for the diagnosis and treatment of bipolar disorders. Long version]. Berlin Heidelberg: Springer; 2013. Available from: http://www.awmf.org/uploads/tx_ szleitlinien/038-0191_S3_Bipolare_Stoerungen_2012-09.pdf. Accessed March 26, 2015. German.
40. DGPPN, BÄK, KBV, et al, eds. S3-Leitlinie,Nationale VersorgungsLeitlinie Unipolare Depression: Kurzfassung; Version 1.3 [S3-Guideline, National Disease Management Guideline Unipolar Depression: Short Version; Version 1.3]. Grünwald: Börm Bruckmeier-Verlag; 2013. Available from: http://www.awmf.org/uploads/tx_szleitlinien/ nvl-005k_S3_Unipolare_Depression_Kurzfassung_2012-01_01.pdf. Accessed March 26, 2015. German.

41. Liebherz S, Härter M, Dirmaier J, Tlach L. Information and decisionmaking needs among people with anxiety disorders: results of an online survey. Patient. Epub 2015 Feb 7.

42. Rössler W, Hoff P, editors. Psychiatrie zwischen Autonomie und Zwang [Psychiatry Between Autonomy and Compulsion]. Heidelberg: Springer Medizin Verlag; 2009. German

43. Puschner B, Neumann P, Jordan H, et al; CEDAR study group. Development and psychometric properties of a five-language multiperspective instrument to assess clinical decision making style in the treatment of people with severe mental illness (CDMS). BMC Psychiatry. 2013;13:48.

44. Mack S, Jacobi F, Gerschler A, et al. Self-reported utilization of mental health services in the adult German population - evidence for unmet needs? Results of the DEGS1-Mental Health Module (DEGS1-MH). Int J Methods Psychiatr Res. 2014;23(3):289-303.

45. Hoffman AS, Volk RJ, Saarimaki A, et al. Delivering patient decision aids on the Internet: definitions, theories, current evidence, and emerging research areas. BMC Med Inform Decis Mak. 2013; 13 Supp1 2:S13.

46. NICE. Depression: The NICE Guideline on the Treatment and Management of Depression in Adults (Updated Edition). National Clinical Practice Guideline 90. Leicester, London: The British Psychological Society and The Royal College of Psychiatrists; 2010.
Patient Preference and Adherence

\section{Publish your work in this journal}

Patient Preference and Adherence is an international, peer-reviewed, open access journal that focuses on the growing importance of patient preference and adherence throughout the therapeutic continuum. Patient satisfaction, acceptability, quality of life, compliance, persistence and their role in developing new therapeutic modalities and compounds to optimize

\section{Dovepress}

clinical outcomes for existing disease states are major areas of interest for the journal. This journal has been accepted for indexing on PubMed Central. The manuscript management system is completely online and includes a very quick and fair peer-review system, which is all easy to use. Visit http://www. dovepress.com/testimonials.php to read real quotes from published authors. 